\title{
Opportunistic agents causing diarrhea in HIV
}

\author{
Varsha Gupta, Gursimran Mohi \\ Department of Microbiology, \\ Government Medical College Hospital, Sector-32, Chandigarh
}

\begin{abstract}
Opportunistic infections (OIs) in Human Immunodeficiency Virus (HIV) infection continue to cause morbidity and mortality in HIV infected patients. Virtually all OIs occur when the CD4+T cell count is less than $200 / \mathrm{mm}^{3}$. The gastrointestinal (GI) tract is a common site for clinical expression of HIV. Diarrhea is the most common GI symptom in HIV/AIDS. Prevalence ranges from $0.9 \%$ to $14 \%$. Diarrhea may be the presenting symptom of lymphoma and Kaposi's sarcoma. It may affect up to $40-50 \%$ of those taking anti-retroviral therapy (ART) and can be induced by other medications. It may also be the result of HIV-associated enteropathy. The agents can be classified as bacterial, parasitic, viral and fungal agents. Almost all bacterial diarrheic agents can cause diarrhea in HIV infected patients, including Clostridium difficile. Intracellular parasites like Isospora belli, Cryptosporidium parvum and Cyclospora are the main causative agents of diarrhea in HIV positive patients. Cytomegalovirus is an AIDS defining opportunistic infection. Candida is the main fungal agent of diarrhea in AIDS. Despite the availability of ART, OIs are common in India as HIV-infected persons in India present with an OI as the initial indicator of their disease. Some of them are aware of their HIV infection but do not take ART and some patients are enrolled in HIV care and prescribed ART but do not attain an adequate virologic and immunologic cure. Thus awareness about optimal strategies for diagnosis, prevention and treatment of OIs in GI tract is essential to provide comprehensive, high quality care for these patients.
\end{abstract}

Keywords: Diarrhea, gastrointestinal tract, HIV/AIDS, opportunistic infections

\section{INTRODUCTION}

Human immunodeficiency virus (HIV) is the causative agent of acquired immunodeficiency syndrome (AIDS). HIV related opportunistic infections (OIs) continue to cause morbidity and mortality in HIV infected patients. Virtually all OIs happen when the CD4+T cell count is less than $200 / \mathrm{mm}^{3}$ and subsequently respond to immune reconstitution facilitated by highly active antiretroviral therapy (HAART). ${ }^{[1-3]}$ The gastrointestinal (GI) tract is a common site for clinical expression of HIV. Progressive immunosuppression is

Corresponding author: Dr. Varsha Gupta

E-mail: varshagupta_99@yahoo.com

Received: 20-09-2016

Accepted: 18-11-2016

How to cite this article: Gupta V, Mohi G. Opportunistic agents causing diarrhea in HIV. J Gastrointest Infect, 2016; 6:22-31 linked to an increase in the prevalence of GI features. Abdominal pain and diarrhea are common in HIV disease. $^{[1]}$ Diarrhea is, however, the most common GI symptom in HIV /AIDS. Prevalence ranges from $0.9 \%$ to $14 \%{ }^{[2,4]}$ Significantly, prevalence is highest in homosexual men and individuals with lower CD4+ T counts. Diarrhea occurs in 30-60\% of patients with AIDS in developed countries and in about $90 \%$ in developing countries. ${ }^{[1]}$ Chronic diarrhea in tropical countries is concomitant with weight loss (slim disease) which according to World Health Organization together with a positive HIV-1 serology test is an AIDS defining norm. ${ }^{[5,6]}$ Diarrhea in AIDS patient is multifactorial. The various agents causing diarrhea are listed in Table 1 . Diarrhea is a common problem for people with HIV in both resource-poor and resource-rich settings, regardless of antiretroviral exposure. In the pre-HAART era, 30-70\% of HIV-seropositive individuals experienced diarrhea, 
Table 1

The infectious causes of diarrhea in HIV/AIDS

\begin{tabular}{|c|c|c|c|c|c|c|}
\hline \multicolumn{2}{|r|}{ Bacteria } & & $\begin{array}{l}\text { Protozoa/Helminths } \\
\text { Cryptosporidium }\end{array}$ & Virus & \multicolumn{2}{|r|}{ Fungus } \\
\hline$?$ & $\begin{array}{l}\text { M ycobacterium avium- } \\
\text { intracellulare }\end{array}$ & $?$ & $\begin{array}{l}\text { Cryptosporidium } \\
\text { Isospora belli }\end{array}$ & $\begin{array}{ll}\text { ? } & \text { Cytomegalovirus } \\
? & \text { Herpes simplex virus }\end{array}$ & $?$ & $\begin{array}{l}\text { Candida } \\
\text { albicans }\end{array}$ \\
\hline$?$ & Salmonella & $?$ & M icrosporidium & ? Adenovirus & $?$ & Histoplasma \\
\hline$?$ & Shigella & $?$ & Enterocytozoon bieneusi & ? Picornavirus & & capsulatum \\
\hline$?$ & Campylobacter & $?$ & Encephalocytozoon & ? HIV & & \\
\hline$?$ & Clostridium difficile & & intestinal is & ? A strovirus & & \\
\hline$?$ & Vibrio parahaemolyticus & $?$ & Leishmaniadonovani & ? Coronavirus & & \\
\hline$?$ & Treponema pallidum & $?$ & Giardia & ? Rotavirus & & \\
\hline$?$ & Spirochaetes & $?$ & Cyclospora & & & \\
\hline ? & N eisseria gonorrheae & $?$ & Entamoeba histolytica & & & \\
\hline ? & Vibrio cholera & $?$ & Strongyloides stercoral is & & & \\
\hline ? & Pseudomonas & & & & & \\
\hline$?$ & Staphylococcus aureus & & & & & \\
\hline ? & M ycobacterium & & & & & \\
\hline & tuberculosis & & & & & \\
\hline
\end{tabular}

and among European patients with CD4+ T counts $<50$ cells $/ 11,49 \%$ would expect to develop diarrhea within 1 year and $96 \%$ within 3 years. ${ }^{[6]}$ In resource-poor areas, incidence and severity continue to be higher. Early clinical observations confirmed that diarrheal illness was linked to reduced quality of life and poorer survival. ${ }^{[7]}$ Diarrhea may be the presenting symptom of lymphoma and Kaposi's sarcoma. It may affect up to $40-50 \%$ of those taking antiretroviral therapy (ART), it can be induced by other medications and may be the result of an incompletely defined direct effect of HIV on the gut mucosa termed HIV-associated enteropathy. ${ }^{[8]}$ AIDS enteropathy was described in 1984 in patients having diarrhea with no detectable pathogen. ${ }^{[9]}$

\section{(i) Bacterial causes}

Various strains of the diarrheagenic E. coli are E. coli enterotoxigenic (ETEC), E. coli enteroaggregative (EAEC), E. coli diffusely adherent (DAEC), E. coli enteroinvasive (EIEC), E. coli enterohemorragic (EHEC) and enteropathogenic E. coli (EPEC). In a study conducted in Nasik, E. coli was the most common bacterial pathogen isolated in HIV seropositive patients. Among the diarrheagenic E. coli isolated, enteropathogenic E. coli was the most common isolate. In HIV seropositive diarrhea patients, E. coli was the most common bacterial isolate $(37 ; 53.6 \%)$ followed by Proteus species $(14 ; 20.2 \%)$ and Pseudomonas species $(10 ; 14.5 \%) .{ }^{[10]}$ Diarrhea in HIV patients with Shigella are at higher risk of developing gastroenteritis. The prevalence of Shigella species was reported $10.5 \%$ for HIV seropositive diarrheic individuals from Southern India. ${ }^{[1]}$ Salmonella was isolated 20 to 100 times more frequently in HIV positive patients. ${ }^{[12]}$ Nontyphoidal Salmonellae (NTS) and Campylobacter jejuni cause prolonged and invasive infection. Recurrent NTS is well thought of as an AIDS defining illness since 1985. ${ }^{[13]}$ Chances of diarrhea in AIDS patients is 39 times higher with C. jejuni. ${ }^{[14]}$ Diarrhea may be associated with disseminated infection with Mycobacterium avium 
Table 2

Prevalence of various etiological agents based on H IV-1 characteristics

\begin{tabular}{|c|l|l|}
\hline 1. & $\begin{array}{l}\text { More common in HIV }-1 \text { infected persons than } \\
\text { in persons without HIV-1 infection }\end{array}$ & $\begin{array}{l}\text { Shigellosis }{ }^{[7]}, \quad \text { Campylobacter }^{[8]} \\
\text { Cryptosporidiosis }^{[9]}\end{array}$ \\
\hline 2. & $\begin{array}{l}\text { Agents causing diarrhea only in HIV }-1 \text { infected } \\
\text { persons }\end{array}$ & $\begin{array}{l}\text { MAC, Cytomegal ovirus, and HIV-1 enteropathy } \\
{[10,11]}\end{array}$ \\
\hline 3. & $\begin{array}{l}\text { In HIV -1 infected persons these agents cause } \\
\text { more severe, prolonged \& recurrent diarrhea }\end{array}$ & $\begin{array}{l}\text { Cryptosporidiosis species, Isosporaspecies, Salmonella species, } \\
\text { Astrovirus, A denovirus, Cal civirus and perhaps M icrosporidium } \\
\text { species, Cyclospora cayetanensis, Shigella species, and } \\
\text { Campylobacter species }\end{array}$ \\
\hline
\end{tabular}

complex, especially in patients with CD4+count less than 50 cells $/ \mathrm{mm}^{3}{ }^{[13]}$ Patients having diarrhea and taking antibiotics should be investigated for Clostridium difficile which is more common in patients having CD4+ count less than 50 cells $/ \mathrm{mm}^{3}{ }^{[15]}$ Invasive NTS was recognized early in the HIV epidemic to be strongly associated with immunosuppression in Western tropical settings, but there is no association between HIV and typhoid or paratyphoid. ${ }^{[1,17]}$ Patients with HIV and NTS infections present with febrile illness or sepsis syndromes and diarrhea may be absent or present as a less prominent feature. ${ }^{[18]}$ As in HIV negative individuals, other bacterial pathogens include $\mathrm{C}$. difficile, Campylobacter species and Shigella species may cause diarrhea. $C$. difficile was the most common cause of diarrhea in a US cohort study and has been described in British and resource-poor settings ${ }^{[19]}$ It has been implicated in over $50 \%$ of cases of acute diarrhea in studies spanning both the pre- and post-HAART eras. Bacteria causing gastroenteritis may cause bloody diarrhea and abdominal pain. Bacteremia is more common, but still unusual, in HIV-related campylobacter and Shigella infections. ${ }^{[20,21]}$ Presenting symptoms of C. difficile infection are similar to HIVseronegative individuals. ${ }^{[2]}$ Case series show that C. difficile infection is no more severe in HIVseropositive individuals though case reports of complications such as toxic megacolon and leukemoid reactions exist as in other populations. ${ }^{[2,23]}$ Sexually transmitted diarrheal pathogens are encountered in patients with multiple sexual partners or receptive anal sex. ${ }^{[24]}$
Initial evaluation should include stool smears and cultures for enteric bacteria. The sample is also sent for C. difficile toxin in the setting of antibiotic usage. It is encouraged to send at least three stool specimens for ova and parasites and acid fast bacilli smear and tuberculosis cultures. However, it has been shown from previous studies that isolation of pathogens is more likely from watery than from formed stools. ${ }^{[25,26]}$

Acute bacterial diarrhea in HIV-seropositive individuals with CD4+counts $>200$ cells $/ \mu 1$ usually does not require treatment, but should be treated when the CD4+ count is $<200$ cells $/ \mu 1$. Acute bacterial diarrhea should be treated as per susceptibility tests and local guidance. $C$. difficile infection should be treated with metronidazole and vancomycin reserved for severe, relapsing or metronidazole nonresponsive infection. . 27,28$]^{2}$ Trimethoprim-sulfamethoxazole reduced the incidence of infectious diarrhea in the pre-HAART era. Retrospective studies suggest that introduction of antiretroviral therapy, including zidovudine monotherapy, has been more effective than targeted antimicrobial prophylaxis in preventing recurrence of NTS, and that duration of antimicrobial prophylaxis, with agents such as fluoroquinolones need not exceed 30 days in patients established on HAART. The incidence of bacterial diarrhea declined steadily after the introduction of HAART, therefore HAART is the mainstay of preventing bacterial diarrhea. ${ }^{[19]}$ Specific therapy is then directed to the enteric pathogen detected. Recurrent infections with Salmonella, Shigella, 
Campylobacter and I sospora will require administration of alternating antibiotics.

Various algorithms have been proposed for the investigation and/or empirical management of chronic HIV-related diarrhea (three or more loose stools for 28 or more days) in Western and tropical settings. ${ }^{[29,30]}$ Parasitic causes are more likely in those with prolonged diarrhea, considerable weight loss and CD4+ count $<100$ cells/pl, and may coexist with cytomegalovirus (CMV), mycobacterial or other infections.

\section{(ii) Parasitic causes}

Parasitic OIs are divided into protozoa and helminths. Isospora belli, Cryptosporidium parvum, Cyclospora which are intracellular parasitic infections are main causative agents of diarrhea in HIV positive patients. ${ }^{[31]}$ In intestinal infections caused by parasites the main defence mechanism is cellular immunity. Thus in HIV positive patients with reduced CD4+ $\mathrm{T}$ lymphocytes, chances of intracellular parasitic infections are more. ${ }^{[32]}$ However, the extracellular parasitic infections caused by Entamoeba histolytica, Giardia intestinalis and Strongyloides stercoralis have also been found as causative agent of diarrhea in HIV positive patients. ${ }^{[3]]}$

C. parvum was first reported as human pathogen in 1975 by Nime ${ }^{[33]}$ C. parvum, C. hominis and C. meleagridis are the important species of cryptosporidiosis causing life threatening gastroenteritis in immunocompromised host. ${ }^{[34]}$ As the CD4+cell count falls below 200 cells/ $\mu 1$ the chances of cryptosporidiosis increases. ${ }^{[35]}$ Mode of transmission of Cryptosporidium is feco-oral route. Infection is spread by drinking water contaminated with oocysts which are resistant to chlorine and being small in size difficult to filter. Ingestion of even 30 oocysts can cause infection. There are reports of infection having occurred with even one oocyst. ${ }^{[36]}$ Cryptosporidium usually resides in small intestine and is minimally invasive in immunocompetent host. The patient present with diarrhea, abdominal cramps, nausea, vomiting, weight loss and fever; these symptoms are self limiting. Whereas in immunocompromised host it can involve epithelial cells of biliary tract, pancreatic duct, stomach, esophagus and respiratory tract. The infection in this group of patient is severe and presents with malabsorption leading to wasting syndrome in HIV positive patients along with jaundice and pancreatitis. ${ }^{[37,38]}$ For diagnosis, three consecutive stool samples are examined. Highly refractile, spherical/oval oocyst measuring $4-5 \mathrm{~mm}$ in diameter are seen in wet mount. Staining is done by modified acid-fast staining, auramine-rhodamine, acridine orange and immunofluorescent antibody (IFA). Other methods are detection of cryptosporidial antigen in the fecal sample by the enzyme-linked immunosorbent assay (ELISA). Polymerase chain reaction (PCR) can also be done and is more sensitive but requires training. ${ }^{[39]}$ The treatment options are limited. Food and Drug Administration has approved nitazoxanide for its treatment. Other pharmacological interventions include treatment with paromomycin and immunotherapy. Passive immunotherapy is done by oral administration of colostrum-derived bovine immunoglobulin. ${ }^{[40]}$ To decrease the incidence of this life threatening diarrheal disease it is very important to reduce its transmission. The chemical method effective for decontamination of water is ozone. Newer approaches are reverse osmosis, membrane filtration, electronic or radiation methods. ${ }^{[4]]}$

There is no specific treatment targeting cryptosporidium directly. Early HAART is imperative and is associated with complete resolution of infection following restoration of immune function. ${ }^{[42,43]}$ In individuals with profuse diarrhea, therapeutic drug monitoring may be required to confirm adequate absorption of antiretroviral agents.

A study combining paromomycin with azithromycin reported substantial reduction in stool frequency and volume, together with diminished oocyst shedding. ${ }^{[4]}$ Paromomycin was given orally as $500 \mathrm{mg}$ four times daily or $1 \mathrm{~g}$ twice daily for up to 12 weeks. The dose of azithromycin was $500 \mathrm{mg}$ daily. However the small numbers in this study and the limited experience of this combination preclude its choice as a front line therapy. Nitazoxanide has been approved for use in immunocompetent individuals but has not been shown to be superior to placebo in the severely immunocompromised. ${ }^{[45]}$ When an anti-cryptosporidial agent is chosen nitazoxanide is the preferred agent but its efficacy is limited in more immunocompromised patients.

Supportive therapy with IV fluid replacement/ antimotility agents is essential. 
- First-line treatment for cryptosporidiosis is with effective ART (category III recommendation).

- Nitazoxanide is effective in adults and children who are not severely immunosuppressed (category II b recommendation).

The use of optimized HAART should be continued to prevent relapse. Standard drinking water chlorination techniques are not sufficient to eradicate the parasite. Specific filtration employing an 'absolute' 1-micron filter is required. ${ }^{[4]}$ Bottled water is not necessarily a safer option. Boiling of water should be advocated.

Microsporidia are unicellular obligate intracellular organisms which were once thought to be parasites but now by molecular phylogeny are placed among fungus. Infective stage is spore form which is highly resistant due to thick double layered spore wall and its mode of infection is ingestion, inhalation, inoculation, rarely transplacental route and is linked to homosexual intercourse. Two most important species found in immunocompromised host are Encephalitozoon species and the species Enterocytozoon bieneusii. It is associated with advanced stage of immunosuppression where CD4+ count is less than $100 / \mathrm{mm}^{3} \cdot^{[47]}$ Most common symptom is diarrhea leading to wasting. The infection spreads from intestinal tract to gall bladder, pancreatic and bile duct, respiratory system as well as the eye. For diagnosis, repetitive examination is advised because of its intermittent shedding. Various staining procedures done are Gram staining, acid fast staining, periodic acid Schiff (PAS) and Giemsa staining. These intracytoplasmic spores are Gram positive, acid fast and PAS positive. Electron microscopy is taken as gold standard. Other methods are carbon immunoassay, indirect IFA test, ELISA, counter immune electrophoresis and Western blotting. ${ }^{[3,3,3]}$

Some species cause GI disturbance, such as diarrhea and cholangitis, and other genera are associated with upper respiratory and ophthalmic infections. The microsporidia most commonly linked to GI illness are Enterocytozoon bieneusi and Encephalitozoon (formerly Septata) intestinalis. Gut infection is acquired by swallowing cysts, usually in water. ${ }^{[4]}$ Pre-HAART studies showed variability in the prevalence of microsporidiosis $(2-70 \%)$ in the immunosuppressed HIV population with diarrhea. ${ }^{[49]}$ The incidence has decreased with the introduction of HAART.
Watery, non-bloody diarrhea, with associated malabsorption, is the commonest presentation of GI infection. Sclerosing cholangitis may occur. Examination of three stools with chromotrope and chemofluorescent stains is often sufficient for diagnosis. If stool samples are consistently negative, a small bowel biopsy should be performed..$^{[49]}$ Stains such as Giemsa, acid-fast or hematoxylin and eosin can be used to visualize microsporidia in biopsy specimens. In disseminated infections due to Encephalitozoon species, organisms may also be found in the deposit of spun urine samples. Electron microscopy remains the gold standard for confirmation and speciation. ${ }^{[50]}$ PCR may be used to identify up to species level.

There is no specific treatment for microsporidial infection. Early HAART is imperative and associated with complete resolution of GI symptoms following restoration of immune function. Therapeutic drug monitoring may be required to confirm adequate absorption of antiretroviral agents. This agent is not currently widely available. Nitazoxanide, albendazole and itraconazole have also been studied. Of these agents, albendazole (400 $\mathrm{mg}$ twice daily for 21 days) is recommended for initial therapy, particularly for E.intestinalis (category III recommendation). ${ }^{[51]}$ Optimized HAART should be used to maintain CD4+ cell counts and prevent relapse.

I. belli now known as Cystoisospora belli was discovered by Rudolf Virchow in 1860 . In India the prevalence of C. belli ranges from $2.5 \%$ to $14 \%$ in HIV positive patients. ${ }^{[52]}$ In immunocompetent hosts the infection is limited to diarrhea, headache, fever, abdominal pain, vomiting, dehydration and weight loss, whereas in immunocompromised hosts diarrhea is more persistent, watery, chronic and associated with extra intestinal manifestations. Mode of infection is by ingestion of food or water contaminated with oocyst.

To diagnose isospora in stool sample, cyst is demonstrated in wet mount or iodine mount. Staining methods which can be used are acid fast staining in which oocyst appear red in color or auraminerhodamine staining. A highly sensitive and specific method for diagnosis is PCR. I. belli has no known animal host but is widespread geographically, causing self-limiting small bowel diarrhea in HIV-seronegative individuals. It is implicated in $10-20 \%$ of cases of chronic 
HIV-related diarrhea in the tropics and is an occasional cause of biliary disease. Treatment traditionally has been with TMP-SMX $960 \mathrm{mg}$ qid PO for 10 days though $960 \mathrm{mg}$ bd appears also to be effective (category III recommendation) and secondary prophylaxis with the same antibiotic (960 mg three times a week) is essential as relapse is common and there is indirect and direct evidence for this. ${ }^{[53,54]}$

Cyclospora cayetanensis, a parasitic infection was first discovered in late 1880s. It is an important cause of traveller's diarrhea and diarrhea in immunocompromised hosts. In immunocompetent hosts, diarrhea is self limiting. But in HIV positive patients and other immunocompromised conditions it can lead to severe intestinal injury, prolonged diarrhea and associated with sequel such as Guillain-Barré syndrome, reactive arthritis syndrome and acalculous cholecystitis. $^{[55]}$ Laboratory diagnosis is done by examination of wet smear, staining with modified acid fast staining and safranine.

The oocysts of $C$. belli are large (20-33 $\mu \mathrm{m} \times 10-19$ $\mu \mathrm{m})$ and ellipsoidal, whereas that of $C$. parvum and Cyclospora cayetanensis are spherical or oval, measuring $4-5 \mu \mathrm{m}$ and $8-10 \mu \mathrm{m}$ respectively. The oocysts of I. belli require 3-4 days and that of $C$. cayetanensis require 5-13 days to mature in environment. On the other hand oocyst of $\mathrm{C}$. parvum are infective as they are passed in feces. ${ }^{[5]}$

C. cayetanensis, a coccidian parasite of the small bowel is widespread throughout the tropics and has caused large outbreaks of food-borne illness in the USA in imported foods. It causes prolonged watery diarrhea that may last for months in patients with HIV, in whom biliary involvement has also been reported. ${ }^{[57]}$

The diagnosis involves the microscopic detection of oocysts but fluorescence microscopy and real-time PCR may be used where available. The clinical and parasitological response to standard doses of TMP-SMX (960 mg twice daily) is rapid and 7 days is usually sufficient. ${ }^{[58]}$

The other two parasitic causes of diarrhea are E. histolytica and G. intestinalis. First discovered in 1875 by Fedor A. Lösch, infection with E. histolytica can lead to amebic liver abscess and colitis. The complications can be ulcerative colitis with toxic dilatation. ${ }^{[59]}$ For diagnosis liver abscess aspiration is useful as it is typical 'anchovy sauce' appearance. Trophozoites can be seen in wet mount preparation of stool sample. Entamoeba infection is most commonly seen in men who have sex with men. ${ }^{[60]}$ Fever, abdominal pain and either watery or bloody diarrhea are the most frequent symptoms and amoebic colitis occurs at a range of $\mathrm{CD}^{+}$counts and is not limited to individuals with CD4+T-cell counts $<200$ cells/ $\mu 1$. Hepatic abscesses are the commonest extraintestinal manifestation. Diagnosis involves microscopy of at least three stool samples for the detection of trophozoites or cysts. Antigen detection or PCR of stool may also be performed and endoscopy with biopsy can aid diagnosis if stool analysis fails to confirm the diagnosis or diagnostic uncertainty remains. Serology can be employed but remains positive for years after exposure and therefore direct identification of Entamoeba is desirable. Extra-intestinal lesions are diagnosed in the appropriate clinical setting by imaging combined with serology. Treatment is most often with metronidazole although tinidazole may be used as an alternative. These agents are followed by diloxanidefuroate or paromomycin both administered for 10 days to eradicate luminal infection.

Giardiasis was first discovered by Van Leeuwenhoek in his own stool in 1600s. Mode of infection is ingestion of contaminated food and water with cyst which is resistant to many disinfectants. The infection is usually asymptomatic; sometimes associated with abdominal cramps, diarrhea, weight loss. Diagnosis is made by microscopic examination of stool for trophozoite and cyst. Giardiasis usually presents with chronic diarrhea with constitutional symptoms. GI symptoms include nausea, bloating, crampy abdominal pain, indigestion and belching. Prolonged diarrhea may result in a malabsorptive state. Giardia species, including G. lamblia, have no increased prevalence in HIV-infected patients, and the clinical presentation and diagnostic methods are also similar to HIV-seronegative patients. ${ }^{[6]]}$ It is well recognized that multiple stool tests obtained on different days may be required for diagnosis as intestinal shedding is sporadic. Giardiasis is treated with metronidazole. Alternatives include albendazole, paromomycin or nitazoxanide. ${ }^{[4]]}$

\section{(iii) Helminthic causes}

Intestinal helminth infections are usually found 
in HIV positive patients; though the prevalence in HIV negative patients is more or less the same. The diagnosis and treatment hence remains same in both the groups. Strongyloides stercoral is was first found in 1876 in GI tract of five soldiers on post mortem examination who were returning from Indochina borders and is called Cochin China diarrhea. ${ }^{[62]}$ It is one of the neglected tropical diseases (NTDs). ${ }^{[63]}$ In India the prevalence is found to be $6.6 \%$ in community based surveys and $11.2 \%$ in hospital based surveys. ${ }^{[64]}$ Laboratory diagnosis of strongyloidiasis involves demonstration of larvae in stool in the wet mount method. Sensitivity of three fecal specimens if screened is $70 \%$. Other methods for diagnosing infection are ELISA, radioallergosorbent test for detection of specific IgE antibodies, indirect immunofluorescence test, complement fixation test, gelatin particle agglutination test and western blot assay. ${ }^{[65]}$ Despite anecdotal reports, there is no conclusive evidence that infection or hyperinfection is more common in patients with HIV, although it may be implicated in immune reconstitution syndromes. ${ }^{[6]]}$

Hook worm causes hypochromic microcytic anemia in many developing countries. It has been found that hookworm infestation was not common in HIV positive anemic adults. ${ }^{[67]}$ Another helminth causing intense pruritus ani; Enterobius vermicularis has been studied in HIV positive patients and significant correlation has been found. ${ }^{[41]}$ Trichuris trichiura is mostly accompanied by protein energy malnutrition and anemia which is also common in HIV positive patients, thus increasing the chances of infestations. ${ }^{[68]}$

\section{(iv) Viral causes}

Viruses are the common cause of diarrhea in HIV positive patients. CMV is an AIDS defining opportunistic infection presenting with diarrhea, weight loss, fever and abdominal pain. ${ }^{[69]}$ Most common site of CMV enteritis is colon. CMV is a member of the herpes family of viruses, usually acquired during childhood. CMV infection remains dormant unless an individual becomes immunosuppressed, when reactivation of latent infection may occur. ${ }^{[70]}$ In the preHAART era, retinitis was the most common presentation of CMV, followed by GI disease. Since the advent of HAART, CMV infection may occasionally occur as part of immune reconstitution syndromes, but the overall incidence of CMV in individuals living with
HIV has dramatically reduced. ${ }^{[71]} \mathrm{CMV}$ may affect all sections of the gut. Endoscopy may reveal classical CMV ulceration of the gut mucosa and biopsy with histopathological review may identify characteristic intranuclear and intracytoplasmic 'owl's eye' inclusions. $^{[72]}$ The absence of ulceration makes a diagnosis of CMV colitis very unlikely. ${ }^{[73]}$

The culture of CMV from biopsy material is not sufficient for the diagnosis of gut infection as immunosuppressed individuals may shed the virus without intestinal disease. First line treatment for CMV colitis is intravenous ganciclovir ( $5 \mathrm{mg} / \mathrm{kg}$ twice daily) for 14-28 days. Immediate optimization of HAART should be considered. CMV colitis has traditionally been treated with ganciclovir $5 \mathrm{mg} / \mathrm{kg}$ bd iv for 14-28 days. ${ }^{[74]}$ Caution should be used in initiating treatment with the oral medication valganciclovir as there is a theoretical concern of decreased absorption, but HIV and non-HIV-related cases of CMV colitis have been successfully treated. ${ }^{[75]}$ Intravenous foscarnet (90 $\mathrm{mg} / \mathrm{kg}$ twice daily) for $14-28$ days is used as an alternative. ${ }^{[6,77]}$ Therapeutic drug monitoring may be required to ensure adequate HAART absorption. Continuous use of effective HAART is required to prevent relapse.

Few studies of HIV-related diarrhea include investigation for viruses other than $\mathrm{CMV}$ and there is only anecdotal evidence of increased severity or frequency of most viruses associated with gastroenteritis in HIV, including noroviruses and rotavirus. ${ }^{[6,7]}$ There have been reports implicating coronavirus, which may coexist with bacterial pathogens in acute diarrhea, and adenovirus, which may coexist with CMV in patients with chronic diarrhea. ${ }^{[2,78]}$ Adenovirus is associated with persistent diarrhea and disseminated infection in AIDS involving brain, lung and liver. ${ }^{[79]}$

Herpes simplex infections (HSV-2 and HSV-1) cause relapsing and severe proctocolitis and should be treated with aciclovir $400 \mathrm{mg}$ five times daily $\mathrm{PO}$ or valaciclovir $1 \mathrm{~g}$ bd PO for 7-14 days, while severe infection may necessitate aciclovir iv $5 \mathrm{mg} / \mathrm{kg}$ tid for the initial part of therapy. ${ }^{[80]}$ Prophylaxis should be considered for recurrent disease. CMV colitis can present with acute diarrhea and is a major opportunistic infection of the GI tract. 


\section{(v) Fungal causes}

Most common fungal cause of diarrhea in HIV positive patients is Candida species. ${ }^{[81]}$ The diarrhea is mostly antibiotic associated. Systemic dimorphic fungi can cause disseminated infections including diarrhea in immunocompromised individuals..$^{[82,83]}$ Thus before the widespread use of potent combination antiretroviral therapy, OIs, which have been defined as infections that are more frequent or more severe because of immunosuppression in HIV-infected persons were the principal cause of morbidity and mortality in this population. In the early 1990s, the use of chemoprophylaxis, immunization, and better strategies for managing acute OIs contributed to improved quality of life and improved survival. Subsequently, the widespread use of potent ART has had the most profound influence on reducing OI-related mortality in HIV infected persons. Despite the availability of ART, OIs continue to cause considerable morbidity and mortality in India due to the following reasons: HIVinfected persons in India are unaware of their HIV infection status and many present with an OI as the initial indicator of their disease. Some individuals are aware of their HIV infection, but do not take ART due to psychosocial or economic factors and some patients are enrolled in HIV care and prescribed ART, but do not attain an adequate virologic and immunologic response due to inconsistent retention in care, poor adherence, unfavorable pharmacokinetics, or unexplained biologic factors. Thus OIs continue to cause substantial morbidity and mortality in HIV-infected persons. Clinicians must be aware of optimal strategies for diagnosis, prevention, and treatment of OIs to provide comprehensive, high quality care for these patients.

\section{REFERENCES}

1. Ambali AP, Murthy S, Mulimani MS. Identification of bacteria causing diarrhoea in HIV/AIDS patients and its correlation with CD4 count. J Evid Based Med Healthc. 2016;3:2165-8.

2. Rossit AR, Gonçalves AC, Franco C, Machado RL. Etiological agents of diarrhea in patients infected by the human immunodeficiency virus-1: a review. Rev Inst Med Trop Sao Paulo. 2009:51:59-65.

3. Wilcox CM. Etiology and evaluation of diarrhea in AIDS: a global perspective at the millennium. World J Gastroenterol. 2000;6:177-86

4. Mayer HB, Wanke CA. Diagnostic strategies in HIV-infected patients with diarrhea. AIDS. 1994;8:1639-48.

5. Colebunders R, Lusakumuni K, Nelson AM, P Gigase, I Lebughe, $E$ van Marck et al. Persistent diarrhoea in Zairian AIDS patients: An endoscopic and histologic study. Gut. 1988;29:1687-91.
6. Cunningham AL, Grohman GS, Harkness J, Law C, Marriott D, Tindall B et al. Gastrointestinal viral infections in homosexual men who were symptomatic and seropositive for human immunodeficiency virus. J Infect Dis. 1988;158:386-91.

7. Cunliffe NA, Gondwe JS, Kirkwood CD, Graham SM, Nhlane NM, Thindwa BD et al. Effect of concomitant HIV infection on presentation and outcome of rotavirus gastroenteritis in Malawian children. Lancet. 2001;358:550-5.

8. Bartlett JG, Belitsos PC, Sears CL. AIDS enteropathy. Clin Infect Dis. 1992;15:726-35

9. Dallabetta GA, Miotti PG. Chronic diarrhoea in AIDS patients in the tropics: a review. Trop Doct. 1992;22:3-9.

10. Thate RN, Deotale V. Bacterial and parasitic etiological agents in HIV seropositive diarrhea cases. IJBAR. 2014;5:523-6.

11. Kownhar $H$, Shankar EM, Rajan R, Vengatesan A, Rao UA. Prevalence of Campylobacter jejuni and enteric bacterial pathogens among hospitalized HIV infected versus non-HIV infected patients with diarrhoeain southern India. Scand J Infect Dis. 2007;39:862-6.

12. Cárcamo C, Hooton T, Wener MH, Weiss NS, Gilman R, Arevalo $J$ et al. Etiologies and manifestations of persistent diarrhea in adults with HIV-1 infection: a case-control study in Lima, Peru. J Infect Dis. 2005;191:11-9.

13. Feasey NA, Healey P, Gordon MA. Review article: the aetiology, investigation and management of diarrhoea in the HIV-positive patient. Aliment PharmacolTher. 2011;34:587-603

14. Sorvillo FJ, Lieb LE, Waterman SH. Incidence of campylobacteriosis among patients with AIDS in Los Angeles County. J Acquir Immune DeficSyndr. 1991;4:598-602.

15. Haines CF, Moore RD, Bartlett JG, Sears CL, Cosgrove SE, Carroll $\mathrm{K}$ et al. Clostridium difficile in a HIV-infected cohort: incidence, risk factors, and clinical out-comes. AIDS. 2013;27:2799-807.

16. Jacobs JL, Gold JW, Murray HW, Roberts RB, Armstrong D. Salmonella infections in patients with the acquired immunodeficiency syndrome. Ann Intern Med. 1985;102:186-8.

17. Beeching NJ, Jones R, Gazzard B. Gastrointestinal opportunistic infections. HIV Medicine. 2011;12:43-54.

18. Chierakul W, Rajanuwong A, Wuthiekanun V, Teerawattanasook $\mathrm{N}$, Simpson A et al. The changing pattern of bloodstream infections associated with the rise in HIV prevalence in northeastern Thailand. Trans R Soc Trop Med Hyg. 2004;98:67886.

19. Sanchez TH, Brooks JT, Sullivan PS, Juhasz M, Mintz E, Dworkin MS et al. Bacterial diarrhea in persons with HIV infection, United States, 1992-2002. Clin Infect Dis. 2005;41:1621-7.

20. Molina J, Casin I, Hausfater P, Giretti E, Welker Y, Decazes J et al. Campylobacter infections in HIV-infected patients: clinical and bacteriological features. AIDS. 1995;9:881-5

21. Baer JT, Vugia DJ, Reingold AL, Aragon T, Angulo FJ, Bradford WZ et al. HIV infection as a risk factor for shigellosis. Emerg Infect Dis. 1999;5:820-3.

22. Bartlett JG. Changing trends in bacterial infections: Staphylococcus aureus, bacterial pneumonia, Clostridium difficile. Top HIV Med. 2007;15:94-8.

23. De Toledo FG, Symes SN. Leukemoid reaction due to Clostridium difficile infection in acquired immunodeficiency syndrome: two case reports and a review of the literature. South Med J. 2004;97:388-92.

24. Surawicz CM, Goodell SE, Quinn TC, Roberts PL, Corey L, Holmes KK et al. Spectrum of rectal biopsy abnormalities in homosexual men with intestinal symptoms. Gastroenterology. 
$1986 ; 91: 651-9$

25. Joshi M, Chowdhary AS, Dalar PJ, Maniar JK. Prevalence of intestinal parasitic pathogens in HIV-seropositive individuals in northern India. Natl Med J India. 2002;15:72-4.

26. Attili SV, Gulati AK, Singh VP, Varma DV, Rai M, Sundar S. Diarrhea, CD4 counts and enteric infections in a hospital-based cohort of HIV-infcted patients around Varanasi, India. BMC Infect Dis. 2006;6:0-0.

27. Lu SS, Schwartz JM, Simon DM, Brandt LJ. Clostridium difficileassociated diarrhea in patients with HIV positivity and AIDS: a prospective controlled study. Am J Gastroenterol. 1994;89:12269.

28. Department of Health and Health Protection Agency. Clostridium difficile infection: how to deal with the problem. Department of Health 2009; Available from http://www.dh.gov.uk/en/ Publicationsandstatistics/Publications/PublicationsPolicyAndGu idance/DH_093220 (last accessed 12 August 2009).

29. Schmidt W, Schneider T, Heise W, Weinke T; Epple H; StöfflerMeilicke $M$ et al. Stool viruses, coinfections, and diarrhea in HIVinfected patients. Berlin Diarrhea/Wasting Syndrome Study Group. J Acquir Immune Defic Syndr Hum Retrovirol. 1996;13:33-8.

30. Gilks CF, Brindle RJ, Otieno LS, Simani PM, Newnham RS, Bhatt SM. Life-threatening bacteraemia in HIV seropositive adults admitted to hospital in Nairobi, Kenya. Lancet. 1990;336:545-9.

31. Fontanet AL, Sahlu T, Rinke de Wit T, Messele T, Masho W, Woldemichael T et al. Epidemiology of infections with intestinal parasites and human immunodeficiency virus (HIV) among sugar-estate residents in Ethiopia. Ann Trop Med Parasitol. 2000;94:269-78.

32. Omalu ICJ, Yako Ab, Duhlinska DD, Anyanwu GI, Pam VA, Inyama PU. First detection of intestinal microsporidia in Nigeria. Online J Health All Sci. 2005;3:4.

33. Nime FA, Burek JD, Page DL, Holscher MA, Yardley JH. Acute enterocolitis in a human being infected with the protozoan Cryptosporidium. Gastroenterology. 1976;70:592-8.

34. Wiwanitkit V. Intestinal Parasite Infestation in HIV Infected Patients. Current HIV Research. 2006;4:87-96.

35. Nissapatorn V, Sawangjaroen N. Parasitic infections in HIV infected individuals: Diagnostic \& therapeutic challenges. Indian J Med Res. 2011;134:878-97.

36. Haas CN, Rose JB. Reconciliation of microbial risk models and outbreak epidemiology: the case of the Milwaukee outbreak. Proceedings of the American Water Works Association. 1994; 517-23.

37. Chen XM, Keithly JS, Paya CV, LaRusso NF. Cryptosporidiosis. N Engl J Med. 2002;346:1723-31.

38. Hunter PR, Nichols G. Epidemiology and clinical features of Cryptosporidium infection in immune compromised patients. Clin Microbiol Rev. 2002;15:145-54.

39. Arora DR, Arora B. AIDS - associated parasitic diarrhoea. Indian J Med Microbiol. 2009;27:185-90

40. Miyamoto Y, Eckmann L. Drug Development against the Major Diarrhea-Causing Parasites of the Small Intestine, Cryptosporidium and Giardia. Front Microbiol. 2015;6:1208.

41. Guerrant RL. Cryptosporidiosis: An Emerging, Highly Infectious Threat. Emerg Infect Dis. 1997;3:51-57.

42. Carr A, Marriott D, Field A, Vasak E, Cooper DA. Treatment of HIV1 -associated microsporidiosis and cryptosporidiosis with combination antiretroviral therapy. Lancet. 1998;351:256-61.

43. Miao YM, Awad-El-Kariem FM, Franzen C, Ellis DS, Müller A,
Counihan $\mathrm{HM}$ et al. Eradication of cryptosporidia and microsporidia following successful antiretroviral therapy. J Acquir Immune Defic Syndr. 2000;25:124-9.

44. Smith NH, Cron S, Valdez LM, Chappell CL, White AC Jr. Combination drug therapy for cryptosporidiosis in AIDS. J Infect Dis. 1998;178:900-3.

45. Fox LM, Saravolatz LD. Nitazoxanide: a new thiazolide anti parasitic agent. Clin Infect Dis. 2005;40:1173-80.

46. Addiss DG, Pond RS, Remshak M, Juranek DD, Stokes S, Davis JP. Reduction of risk of watery diarrhea with point-of-use water filters during a massive outbreak of waterborne Cryptosporidium infection in Milwaukee, Wisconsin, 1993. Am J Trop Med Hyg. 1996;54:549-53.

47. Mathis A, Weber R, Deplazes P. Zoonotic potential of the microsporidia. Clin Microbiol Rev. 2005;18:423-45.

48. Didier ES. Microsporidiosis: an emerging and opportunistic infection in humans and animals. Acta Trop. 2005;94:61-76.

49. Weiss LM, Vossbrinck CR. Microsporidiosis: molecular and diagnostic aspects. Adv Parasitol. 1998;40:351-95.

50. Maggi P, Larocca AM, Quarto M, Serio G, Brandonisio O, Angarano G. Effect of antiretroviral therapy on cryptosporidiosis and microsporidiosis in patients infected with human immunodeficiency virus type 1. Eur J ClinMicrobiol Infect Dis. 2000;19:213-7.

51. Molina JM, Chastang C, Goguel J, Sarfati C, et al. Albendazole for treatment and prophylaxis of microsporidiosis due to Encephalitozoon intestinalis in patients with AIDS: a randomized double-blind controlled trial. J Infect Dis. 1998;177:1373-7.

52. Gautam N, Khurana S, Sharma A, Sehgal R. Isosporiasis in a tertiary care center of North India. Indian J Pathol Microbiol. 2014:57;272-4.

53. Pape JW, Verdier RI, Johnson WD. Treatment and prophylaxis of Isospora belli infections in patients with the acquired immunodeficiency syndrome. New Engl J Med. 1989;320:10447.

54. Sorvillo FJ, Leib LE, Seidel J, Kerndt P, Turner J, Ash LR. Epidemiology of isosporiasis among persons with acquired immunodeficiency syndrome in Los Angeles County. Am J Trop Med Hyg. 1995;53:656-9.

55. Shields JM, Olson BH. Cyclospora cayetanensis: a review of an emerging parasitic coccidian. Int J Parasitol. 2003:33;371-91.

56. Verweij JJ, Laeijendecker $\mathrm{D}$, Brienen $\mathrm{EA}$, van Lieshout $\mathrm{L}$, Polderman AM. Detection of Cyclospora cayetanensis in travellers returning from the tropics and subtropics using microscopy and real-time PCR. Int $J$ Med Microbiol. 2003;293:199-202.

57. Pape JW, Verdier RI, Boncy M, Boncy J, Johnson WD. Cyclospora infection in adults infected with HIV: clinical manifestations, treatment, and prophylaxis. Ann Intern Med. 1994;121:654-7.

58. Verdier RI, Fitzgerald DW, Johnson WD Jr, Pape JW. Trimethoprim-sulfamethoxazole compared with ciprofloxacin for treatment and prophylaxis of Isospora belli and Cyclospora cayetanensis infection in HIV-infected patients: a randomized, controlled trial. Ann Intern Med. 2000;132:885-8.

59. Sturgess I, Greenfield SM, Teare J, O'Doherty MJ. Ulcerative colitis developing after amoebic dysentery in a haemophiliac patient with AIDS. Gut. 1992;33:408-10.

60. Hung CC, Ji DD, Sun HY, Lee YT, Hsu SY, Chang SY et al. Increased risk for Entamoeba histolytica infection and invasive amebiasis in HIV seropositive men who have sex with men in Taiwan. PLoSNegI Trop Dis. 2008;2(2):e175. 
61. Wilcox CM, Wilcox \& Moe Nkemueller KE. Review article: the therapy of gastrointestinal infections associated with the acquired immunodeficiency syndrome. Aliment Pharmacol Ther. 1997;11:425-43.

62. Kandi $V$ and Bhatti $A B$. Human Strongyloidiasis: An Insight in to a Neglected Tropical Parasitic Disease. Transl Biomed. 2015,6:4

63. Olsen A, van Lieshout L, Marti H, Polderman T, Polman K, Steinmann $\mathrm{P}$ et al. Strongyloidiasis-the most neglected of the neglected tropical diseases? Trans $\mathrm{R}$ Soc Trop Med Hyg. 103:967-72.

64. Schär F, Trostdorf U, Giardina F et al. Strongyloides stercoralis: Global Distribution and Risk Factors. PLoSNegl Trop Dis. 2013;7:e2288.

65. Siddiqui AA, Berk SL. Diagnosis of Strongyloidesstercoralis infection. Clin Infect Dis. 2001;33:1040-7.

66. Viney ME, Brown M, Omoding NE, Bailey JW, Gardner MP, Roberts E, et al. Why does HIV infection not lead to disseminated strongyloidiasis? J Infect Dis. 2004;190:2175-80.

67. Lewis DK, Whitty CJ, Walsh AL, Epino H, Broek NR, Letsky EA et al. Treatable factors associated with severe anaemia in adults admitted to medical wards in Blantyre, Malawi, an area of high HIV seroprevalence. Transactions of the Royal Society of Tropical Medicine and Hygiene. 2005;99:561-7.

68. Stephenson LS, Holland CV, Cooper ES. The public health significance of Trichuris trichiura. Parasitology. 2000;121.S73S95.

69. Gertler SL, Pressman J, Price P, Brozin- sky S, Miyai K. Gastrointestinal cytomegalovirus infection in a homosexual man with severe acquired immunodeficiency syndrome. Gastroenterology. 1983;85:1403-6.

70. Gallant JE, Moore RD, Richman DD, Chaisson RE. Incidence and natural history of cytomegalovirus disease in patients with advanced human immunodeficiency virus disease treated with zidovudine. The Zidovudine Epidemiology Study Group. J Infect Dis. 1992;166:1223-7.

71. Shepp DH, Moses JE, Kaplan MH. Seroepidemiology of cytomegalovirus in patients with advanced HIV disease: influence on disease expression and survival. J Acquir Immune Defic Syndr Hum Retrovirol. 1996;11:460-8.
72. Dieterich DT, Rahmin M. Cytomegalovirus colitis in AIDS: presentation in 44 patients and a review of the literature. J Acquir Immun Defic Syndr. 1991;4(Suppl. 1):S29-35.

73. Mentec $\mathrm{H}$, Leport $\mathrm{C}$, Leport J, Marche C, Harzic M, Vildé JL. Cytomegalovirus colitis in HIV-1-infected patients: a prospective research in 55 patients. AIDS. 1994;8:461-7.

74. Dieterich DT, Kotler DP, Busch DF, Crumpacker C, Du Mond C, Dearmand B et al. Ganciclovir treatment of cytomegalovirus colitis in AIDS: a randomized, double-blind, placebo-controlled multicenter study. J Infect Dis. 1993;167:278-82.

75. Siegal DS, Hamid N, Cunha BA. Cytomegalovirus colitis mimicking ischemic colitis in an immunocompetent host. Heart Lung. 2005;34:291-4.

76. Blanshard C, Benhamou Y, Dohin E, Lernestedt JO, Gazzard BG Katlama C. Treatment of AIDS-associated gastrointestinal cytomegalovirus infection with foscarnet and ganciclovir: a randomized comparison. J Infect Dis. 1995;172:622-8.

77. Nelson MR, Connolly GM, Hawkins DA, Gazzard BG. Foscarnet in the treatment of cytomegalovirus infection of the esophagus and colon in patients with the acquired immune deficiency syndrome. Am J Gastroenterol. 1991;86:876-81.

78. Thomas PD, Pollok RC, Gazzard BG. Enteric viral infections as a cause of diarrhoea in the acquired immunode?ciency syndrome. HIV Med. 1999;1:19-24.

79. Marcela Echavarría. Adenoviruses in Immunocompromised. Hosts Microbiol Rev. 2008;21:704-15.

80. Drew WL, Buhles W, Erlich KS. Herpes virus infections (cytomegalovirus, herpes simplex virus, varicella zoster virus). How to use ganciclovir (DHPG) and acyclovir. Infect Dis Clin North Am. 1988;2:495-509.

81. Uppal B, Kashyap B, Bhalla P. Enteric pathogens in HIV / AIDS from a tertiary care hospital. Indian $\mathrm{J}$ Community Med. 2009;34:237-42.

82. Vaishnavi C, Kaur S, Prakash S. Speciation of fecal Candida isolates in antibiotic-associated diarrhea in non-HIV patients. Jpn J Infect Dis. 2008;61:1-4.

83. Casotti JA, Motta TQ, Ferreira CU Jr, Cerutti C Jr. Disseminated histoplasmosis in HIV positive patients in Espirito Santo state, Brazil: a clinical-laboratory study of 12 cases (1999-2001). Braz J Infect Dis. 2006;10:327-30. 